\title{
The role of benznidazole with cyanocobalamin and ascorbic acid in treating the chronic phase of Chagas disease
}

\author{
Mohamed Amin Ghobadifar ${ }^{[1]}$, Navid Kalani ${ }^{[1]}$, Marzieh Gitiforouz $^{[2]}$ \\ and Zahra Mosallanejad ${ }^{[3]}$
}

[1]. Department of Student Research Committee, Jahrom University of Medical Sciences, Jahrom, Iran. [2]. Department of Student Research Committee, Fasa University of Medical Sciences, Fasa, Iran. [3]. Department of Gynecology and Obstetrics, Shiraz University of Medical Sciences, Shiraz, Iran.

Dear Editor,

We were recently intrigued by an article published in Revista da Sociedade Brasileira de Medicina Tropical/Journal of the Brazilian Society of Tropical Medicine by Andrade et al., entitled Clinical and serological evolution in chronic Chagas disease patients in a 4-year pharmacotherapy followup: a preliminary study $y^{1}$. The authors presented an interesting investigation of the role of benznidazole (Bnz) in managing the chronic phase of Chagas disease, and concluded that Bnz is beneficial for patients experiencing the chronic phase of Chagas disease. Although Bnz is the current reference drug for the acute phase of Chagas disease, the results are unsatisfactory, given the limited efficacy and toxic side effects, such as vomiting, anorexia, allergic dermopathy, and peripheral polyneuropathy. In contrast, ascorbic acid and cyanocobalamin are over-thecounter drugs that rarely present side effects. Andrade et al. ${ }^{1}$ are to be congratulated for conducting such a comprehensive study regarding the significant role of Bnz in treating the chronic phrase of Chagas' disease. To their discussion, we also note the efficacy of Bnz combined with cyanocobalamin and ascorbic acid, which is evident in the results discussed below.

Some studies have reported that levels of ascorbatedependent antioxidative enzymes, which use the ascorbic acid that exists in infected tissues, are decreased during some parasitic infections, as the parasites use this mechanism to protect themselves from the oxidizing action of reactive nitrogen species and reactive oxygen species (ROS) that are produced by the host's inflammatory cells ${ }^{2,3}$.

For example, Marim et al. ${ }^{4}$ have reported that orally administered high-dose ascorbic acid can cause the clearance of trypanosomes, especially trypomastigotes. As well, Ciccarelli et al. ${ }^{5}$ have demonstrated that cyanocobalamin markedly decreased the motility and growth rate of Trypanosoma cruzi epimastigotes, where its cytotoxic action is thought to occur through the generation of ROS. Moreover, ascorbate peroxidase

Address to: Dr. Mohamed Amin Ghobadifar. Department of Student Research Committee/Medicine School/Jahrom University of Medical Sciences. Motahari Avenue, Jahrom, Iran.

Phone: 98936 620-8078; Fax: 98711 636-1386

e-mail: amin_m505@yahoo.com

Received 17 April 2014

Accepted 21 May 2014 activity is significantly increased by cyanocobalamin, and ascorbic acid is known to intensify the antiparasitic activity of cyanocobalamin. This mechanism of action is likely due to the well-known prooxidant effects of these compounds, which, when combined with transition metal ions $(\mathrm{Co}, \mathrm{Cu}$, and $\mathrm{Fe})$, generate $\operatorname{ROS}^{6}$. Accordingly, in the study of Ciccarelli et al..$^{5}$, the antiparasitic effect of Bnz treatment was further enhanced by the coadministration of cyanocobalamin and ascorbic acid. As well, it has previously be reported that the that treatment of blood infected with Trypanosoma cruzi with ascorbic acid, light, and gentian violet effectively prevents transmission of Chagas disease ${ }^{7}$.

Thus, we believe that it is worthwhile to assess the effect of Bnz combined with ascorbic acid and cyanocobalamin as a novel therapeutic modality for treating the chronic phase of Chagas disease.

\section{CONFLICT OF INTEREST}

The authors declare that there is no conflict of interest.

\section{REFERENCES}

1. Andrade MC, Oliveira MF, Nagao-Dias AT, Coelho IC, Candido DS, Freitas EC, et al. Clinical and serological evolution in chronic Chagas disease patients in a 4-year pharmacotherapy follow-up: a preliminary study. Rev Soc Bras Med Trop 2013; 46:776-778.

2. Logan FJ, Taylor MC, Wilkinson SR, Kaur H, Kelly JM. The terminal step in vitamin C biosynthesis in Trypanosoma cruzi is mediated by a FMNdependent galactonolactone oxidase. Biochem J 2007; 407:419-426.

3. Monteiro G, Horta BB, Pimenta DC, Augusto O, E Netto L. Reduction of 1-Cys peroxiredoxins by ascorbate changes the thiol-specific antioxidant paradigm, revealing another function of vitamin $\mathrm{C}$. Proc Natl Acad Sci 2007; 104:4886-4891.

4. Marim RG, Gusmao AS, Castanho RE, Deminice R, Therezo AL, Jordão Junior AA, et al. Effects of vitamin C supplementation on acute phase Chagas disease in experimentally infected mice with Trypanosoma cruzi QM1 strain. Rev Inst Med Trop São Paulo 2012; 54:319-323.

5. Ciccarelli AB, Frank FM, Puente V, Malchiodi EL, Batlle A, Lombardo ME. Antiparasitic Effect of Vitamin B12 on Trypanosoma cruzi. Antimicrob Agents Chemother 2012; 56:5315-5320.

6. Solovieva ME, Soloviev VV, Akatov VS. Vitamin B12b increases the cytotoxicity of short-time exposure to ascorbic acid, inducing oxidative burst and iron-dependent DNA damage. Eur J Pharmacol 2007; 566:206-214.

7. Ramirez LE, Lages-Silva E, Pianetti GM, Rabelo RM, Bordin JO, Moraes-Souza H. Prevention of transfusion-associated Chagas' disease by sterilization of Trypanosoma cruzi-infected blood with gentian violet, ascorbic acid, and light. Transfusion 1995; 35:226-230. 